\title{
Oral hygiene status in a general population of Iran, 2011: a key lifestyle marker in relation to common risk factors of non-communicable diseases
}

\author{
Fereshteh Asgari ${ }^{1}$, Azam Majidi ${ }^{2}$ Jalil Koohpayehzadeh ${ }^{3}$, Koorosh Etemad ${ }^{4}$, Ali Rafei ${ }^{*}$
}

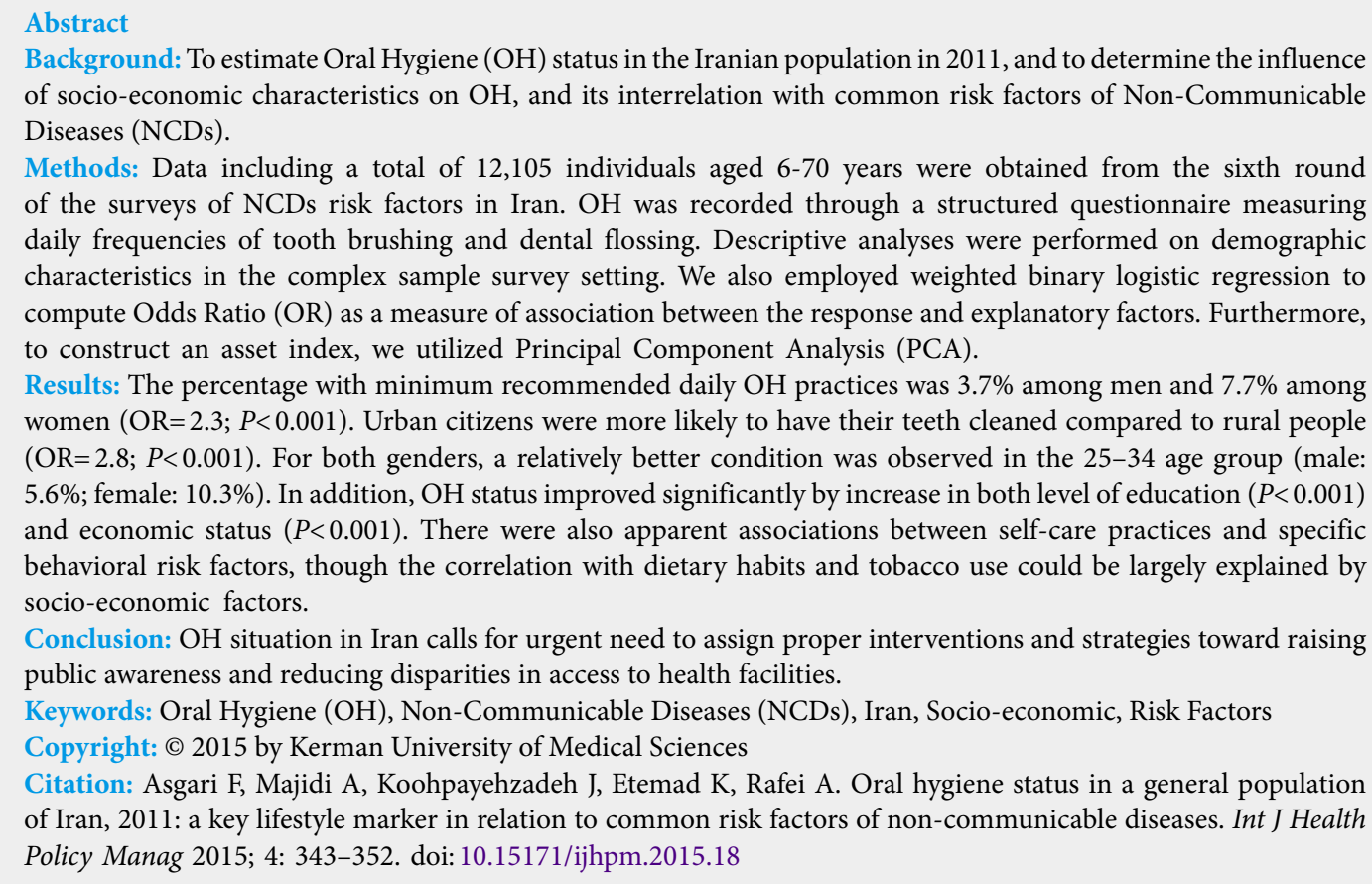

Background: To estimate Oral Hygiene $(\mathrm{OH})$ status in the Iranian population in 2011, and to determine the influence of socio-economic characteristics on $\mathrm{OH}$, and its interrelation with common risk factors of Non-Communicable Diseases (NCDs).

Methods: Data including a total of 12,105 individuals aged 6-70 years were obtained from the sixth round of the surveys of NCDs risk factors in Iran. $\mathrm{OH}$ was recorded through a structured questionnaire measuring daily frequencies of tooth brushing and dental flossing. Descriptive analyses were performed on demographic characteristics in the complex sample survey setting. We also employed weighted binary logistic regression to compute Odds Ratio (OR) as a measure of association between the response and explanatory factors. Furthermore, to construct an asset index, we utilized Principal Component Analysis (PCA).

Results: The percentage with minimum recommended daily $\mathrm{OH}$ practices was $3.7 \%$ among men and $7.7 \%$ among women $(\mathrm{OR}=2.3 ; P<0.001)$. Urban citizens were more likely to have their teeth cleaned compared to rural people $(\mathrm{OR}=2.8 ; P<0.001)$. For both genders, a relatively better condition was observed in the 25-34 age group (male: 5.6\%; female: $10.3 \%)$. In addition, $\mathrm{OH}$ status improved significantly by increase in both level of education $(P<0.001)$ and economic status $(P<0.001)$. There were also apparent associations between self-care practices and specific behavioral risk factors, though the correlation with dietary habits and tobacco use could be largely explained by socio-economic factors.

Conclusion: $\mathrm{OH}$ situation in Iran calls for urgent need to assign proper interventions and strategies toward raising public awareness and reducing disparities in access to health facilities.

Keywords: Oral Hygiene (OH), Non-Communicable Diseases (NCDs), Iran, Socio-economic, Risk Factors

Copyright: @ 2015 by Kerman University of Medical Sciences

Citation: Asgari F, Majidi A, Koohpayehzadeh J, Etemad K, Rafei A. Oral hygiene status in a general population of Iran, 2011: a key lifestyle marker in relation to common risk factors of non-communicable diseases. Int J Health Policy Manag 2015; 4: 343-352. doi: 10.15171/ijhpm.2015.18

Article History:

Received: 30 September 2014 Accepted: 28 January 2015 ePublished: 30 January 2015

\section{Key Messages}

Implications for policy makers

- Oral Hygiene $(\mathrm{OH})$ is in an alarming situation in Iran, so urgent efforts should be devoted to promote $\mathrm{OH}$.

- Both education and wealth significantly affect $\mathrm{OH}$. Thus, strategies for raising public awareness should be designed and implemented.

- Poor $\mathrm{OH}$ is associated with behavioral risk factors due to low socio-economic levels.

Implications for public

Most of the dental problems can be prevented by taking the recommendations of tooth brushing twice or more a day and flossing at least once a day.

\section{Background}

Unhealthy lifestyle leads to a rapid growth in NonCommunicable Diseases (NCDs) globally (1). The population-based primary prevention through focusing on the major risk factors identification is an essential strategy to face NCDs global epidemic. Overall, World Health Organization (WHO) highlights eight common risk factors as the leading causes of NCDs (2). Among behavioral risk factors, tobacco use, physical inactivity, poor dietary habits and alcohol consumption together kill 12 million people annually and undertake $11 \%$ of the global burden of disease and risk factors (3). Population explosion, increasing rate of urbanization, aging phenomenon and inequality in socioeconomic determinants account for the major factors that contribute to the globalization of unhealthy lifestyle (4-7). WHO recommends countries to implement the STEPwise approach to Surveillance (STEPS) that provides standard data to not only within-country monitoring of risk factors causing NCDs, but also between-country comparisons (2).

Oral Hygiene $(\mathrm{OH})$ is another key component of lifestyle. Most oral problems mainly cavities and gingivitis result from poor $\mathrm{OH}$. In the other side, oral health significantly affects general health and quality of life (8-10). Oral health may also be influenced by poor nutrition, smoking and alcohol intake.

Full list of authors' affiliations is available at the end of the article. 
From this viewpoint, oral diseases appear to be associated with NCDs as a result of shared risk factors. In addition, recent findings emphasize on the relationship between dental caries and some cancers e.g. head and neck and gastric cancers as well (11-14). However, as recommended by American Dental Association (ADA), regular habits of tooth brushing ( $\geq$ twice a day) and flossing ( $\geq$ once a day) can effectively prevent these conditions (15).

While the world is obsessed with NCDs, oral diseases has been widely neglected (16) and limited to treatment rather than prevention (17). Approximately all adult population in the world suffers from dental caries. Oral conditions are currently responsible for 15 million DALYs (increased 20.8\% between 1990-2010), costing 224 years of life per 100,000 people (18-21). In the other side, oral diseases rank as the fourth most expensive diseases to be treated in almost every country (22). Globally, the greatest burden of oral diseases is on the socially marginalized and poor people (23-33). To tackle this public health issue in favor of human's life $\mathrm{OH}$ should be taken into consideration (34-39).

Although STEPS suggests measuring $\mathrm{OH}$ as an optional module, it has only been included in the latest (sixth) round of the study in Iran. In the present study, we aimed to estimate the $\mathrm{OH}$ status in different subpopulations of Iran in order to identify groups with poorer conditions for the subsequent interventions. Then, its association with socio-demographic and -economic factors was taken into account. Besides, we attempted to consider the relationship between $\mathrm{OH}$ and fruit/ vegetable intake, physical activity, tobacco use, obesity and hypertension, in a sense that the confounding role of SocioEconomic Status (SES) is likely to make this association significant, i.e. the lower degrees of SES may predispose people to both poor $\mathrm{OH}$ and common NCD risk factors.

\section{Methods \\ Study area and data source}

Data for this study were obtained from the sixth round of the national NCD risk factors surveys in Iran. This populationbased cross-sectional study was conducted in 2011 by Iran's Center for Diseases Control collaboratively with 51 medical schools throughout Iran. A sample of 12,105 noninstitutionalized individuals aged between 6 and 70 years was taken through a multi-stage cluster random sampling scheme. Districts were initially assumed to be Primary Sampling Units (PSU), and 50 out of them were randomly selected using the systematic proportional-to-size probability technique. Each selection in this stage was assumed to represent 12 clusters as Secondary Sampling Units (SSUs) in the next step. Then, with the same method, clusters, each including 20 persons, were distributed within districts. Households were Sample Listing Units (SLUs), and their postal addresses were extracted by Iran's Post Company. Within households, maximum of two persons, one $<55$ and the other $\geq 55$ years old were chosen by use of a KISH selection method. Eligible subjects were eventually interviewed at their homes by trained staff after receiving an inform consent.

\section{Measurements and variables}

We employed a standard questionnaire proposed by WHO stepwise approach to NCDs Risk Factors Surveillance
(STEPS) mainly including demographic information, behavioral risk factors and physical measurements. Gender, age, residential area, job and level of education were recorded as demographic information. Moreover, to assess individuals' assets, participants were asked about the area of the house they live in, and also whether they own separate bathroom, kitchen, vacuum machine, personal computer, fridge and washing machine. Detailed questions were assigned to assess daily habits of diet, physical activity and tobacco use as behavioral risk factors. Then, weight, height and blood pressure (three repeated measures) were quantified in the final step. In particular, a couple of questions were allocated to evaluate daily $\mathrm{OH}$ habits. For this section, participants were asked "how often do they brush/floss their teeth daily?" there were three possible choices: never, once a day and twice or more a day.

Definitions

Poor $\mathrm{OH}$ was defined for individuals who did not clean their teeth by brushing at least twice and flossing once daily. Individuals whose daily consumption of fruit and/ or vegetable was $<5$ servings were considered to be on an unhealthy diet. Participant with $<600$ MET-Minutes activities per week were categorized as physically inactive. Obesity was defined as Body Mass Index $(\mathrm{BMI}) \geq 30 \mathrm{Kg} / \mathrm{m}^{2}$. Hypertension was also defined for people who had Systolic Blood Pressure (SBP) $\geq 140 \mathrm{mmHg}$ and/or Diastolic Blood Pressure (DBP) $\geq 90 \mathrm{mmHg}$.

\section{Statistical Analysis}

After data screening, individuals' sampling weights were computed by product of the selection probabilities in each step. Complex sample survey analysis was used to estimate the prevalence rates of dental care habits and associated 95\% Confidence Intervals (95\% CIs) within the subpopulations. To measure the association between $\mathrm{OH}$ and relevant factors, Odds Ratio (OR) was estimated through a weighted binary logistic regression model. We also utilized Principal Component Analysis (PCA) to categorize people into the economic quartiles. Furthermore, Cochran-Armitage test was used to examine the trends of dental care habits frequencies over educational levels and economic status. All computations and statistical tests were performed in Stata/SE 11.0 (StataCorp, College Station, TX, USA).

\section{Results}

After discarding missing and invalid data, 12,077 records remained, of which 5,127 (42.5\%) were males and 6,949 (57.5\%) were females. About 8,324 (69\%) were urban citizens and $3,753(31 \%)$ were living in rural regions. The majority of participants were Persian (48.9\%), and were engaged in homemaking (30.3\%); 14\% were also university graduates. The mean and standard error of sample's age were estimated 37.8 and 0.2 years respectively. Moreover, the response rate of the study was $95.3 \%$.

Daily tooth brushing and dental flossing frequencies have been summarized in Table 1. As illustrated, totally $20.1 \%$ of Iranian people brush their teeth twice a day or more and $16.8 \%$ floss at least once a day. In addition, our findings generally show that Iranian women keep their teeth clean 
Table 1. Relative frequencies of daily tooth brushing and dental flossing habits by gender groups

\begin{tabular}{|c|c|c|c|c|c|c|c|c|c|c|}
\hline \multirow{2}{*}{\multicolumn{2}{|c|}{$\mathrm{OH}$ frequency per day }} & \multicolumn{3}{|c|}{ All } & \multicolumn{3}{|c|}{ Male } & \multicolumn{3}{|c|}{ Female } \\
\hline & & Number & $\%$ & $95 \% \mathrm{Cl}$ & Number & $\%$ & $95 \% \mathrm{Cl}$ & Number & $\%$ & $95 \% \mathrm{Cl}$ \\
\hline \multirow{3}{*}{$\begin{array}{l}\text { Tooth } \\
\text { Brush }\end{array}$} & Never & 4,280 & 32.5 & $28.4-36.8$ & 2,197 & 39.7 & $37.1-42.3$ & 2,083 & 25.0 & $23.3-26.8$ \\
\hline & Once & 5,423 & 47.4 & $44.3-50.5$ & 2,245 & 46.4 & $44.5-48.3$ & 3,178 & 48.5 & $47.0-49.9$ \\
\hline & Twice or more & 2,364 & 20.1 & $17.7-22.7$ & 681 & 13.9 & $12.8-15.2$ & 1,683 & 26.5 & $25.1-28.0$ \\
\hline \multirow{3}{*}{$\begin{array}{l}\text { Dental } \\
\text { Floss }\end{array}$} & Never & 10,145 & 83.2 & $79.4-86.4$ & 4,456 & 86.1 & $84.6-87.5$ & 5,689 & 80.1 & $77.9-82.2$ \\
\hline & Once & 1,513 & 13.4 & $10.8-16.4$ & 555 & 11.6 & $10.3-12.9$ & 958 & 15.3 & $13.7-16.9$ \\
\hline & Twice or more & 407 & 3.4 & $2.7-4.3$ & 114 & 2.3 & $2.0-2.6$ & 293 & 4.6 & $4.0-5.2$ \\
\hline
\end{tabular}

$\mathrm{OH}=$ Oral Hygiene; $\mathrm{Cl}=$ Confidence Interval

much more than men. Percentage who did not have daily brushing habit was significantly greater for men compared to women (male: $39.7 \%$; female: $25.0 \%$; $P<0.001$ ). Women also more than men had daily habit of flossing (male: $4.6 \%$; female: $2.3 \% ; P<0.001)$.

Table 2 presents the percentages who brush their teeth twice or more a day, floss at least once a day, and those who have both habits along with related ORs corresponding to each subpopulation. The odds of $\mathrm{OH}$ in women is noted to be more than twice relative to men $(\mathrm{OR}=2.3 ; P<0.001)$. For rural and urban regions, percentage of people who pursue daily recommendations of oral self-care were computed $2.9 \%$ and $6.9 \%(P<0.001)$ respectively. Compared to rural people, urban citizens are nearly three times more likely to care for their teeth $(\mathrm{OR}=2.7 ; P<0.001)$. Figure 1 depicts not only this difference by sex groups, but also higher inequality of $\mathrm{OH}$ between sex groups in urban areas in contrast to their rural counterparts.

Figure 2 exhibits the percentage of people who both brush more than once a day and floss at least once a day over age groups. It clearly demonstrates that $\mathrm{OH}$ develops over age groups with a peak at age 25-34 years, and then gradually decreases. Findings of ORs over age groups in Table 2 show similar results. Besides, for all age groups women received

Table 2. Relative frequencies of dental self-care behaviors by gender, residential area, age groups,ethnicity and job categories

\begin{tabular}{|c|c|c|c|c|c|c|c|c|c|c|c|c|}
\hline \multirow{2}{*}{ Variable } & \multicolumn{4}{|c|}{ Brush $\geq$ twice/day } & \multicolumn{4}{|c|}{ Floss $\geq$ once/day } & \multicolumn{4}{|c|}{ Both habits/day } \\
\hline & Number & $\%$ & OR $^{\mathrm{a}}$ & $P$ & Number & $\%$ & OR $^{\mathrm{a}}$ & $P$ & Number & $\%$ & OR $^{\mathrm{a}}$ & $P$ \\
\hline \multicolumn{13}{|l|}{ Gender } \\
\hline Male & 681 & 13.9 & 1.0 & - & 669 & 13.8 & 1.0 & - & 183 & 3.7 & 1.0 & - \\
\hline Female & 1,683 & 26.5 & 2.2 & 0.000 & 1,251 & 19.9 & 1.6 & 0.000 & 483 & 7.7 & 2.3 & 0.000 \\
\hline \multicolumn{13}{|l|}{ Residential area } \\
\hline Rural & 546 & 15.1 & 1.0 & --- & 327 & 9.5 & 1.0 & --- & 93 & 2.9 & 1.0 & --- \\
\hline Urban & 1,818 & 22.3 & 1.6 & 0.000 & 1,593 & 19.9 & 2.4 & 0.000 & 573 & 6.9 & 2.7 & 0.000 \\
\hline \multicolumn{13}{|l|}{ Age Group } \\
\hline $06-14$ & 179 & 14.3 & 1.0 & - & 121 & 9.4 & 1.0 & - & 35 & 2.7 & 1.0 & - \\
\hline $15-24$ & 562 & 23.0 & 1.9 & 0.000 & 409 & 17.8 & 2.1 & 0.000 & 149 & 6.0 & 2.4 & 0.000 \\
\hline $25-34$ & 603 & 25.0 & 2.2 & 0.000 & 532 & 21.6 & 2.8 & 0.000 & 197 & 7.9 & 3.3 & 0.000 \\
\hline $35-44$ & 333 & 20.5 & 1.7 & 0.000 & 347 & 20.9 & 2.7 & 0.000 & 115 & 6.9 & 2.9 & 0.000 \\
\hline $45-54$ & 269 & 16.0 & 1.2 & 0.050 & 244 & 14.2 & 1.7 & 0.000 & 87 & 4.6 & 1.9 & 0.003 \\
\hline $55-64$ & 323 & 14.6 & 1.0 & 0.638 & 213 & 10.3 & 1.1 & 0.375 & 65 & 3.4 & 1.3 & 0.229 \\
\hline $65-70$ & 95 & 10.5 & 0.7 & 0.052 & 54 & 7.3 & 0.8 & 0.189 & 18 & 2.0 & 0.8 & 0.443 \\
\hline \multicolumn{13}{|l|}{ Ethnicity } \\
\hline Parsian & 1,266 & 21.4 & 1.0 & - & 1,016 & 18.2 & 1.0 & - & 379 & 6.4 & 1.0 & - \\
\hline Azeri & 394 & 16.5 & 0.7 & 0.000 & 431 & 17.3 & 0.9 & 0.139 & 110 & 4.6 & 0.7 & 0.001 \\
\hline Lur & 177 & 17.5 & 0.8 & 0.022 & 147 & 16.9 & 0.8 & 0.149 & 55 & 5.8 & 0.8 & 0.170 \\
\hline Kurd & 179 & 19.9 & 0.9 & 0.385 & 120 & 12.7 & 0.7 & 0.000 & 38 & 4.3 & 0.6 & 0.017 \\
\hline Balouch & 94 & 21.0 & 1.0 & 0.827 & 40 & 10.6 & 0.5 & 0.004 & 14 & 4.8 & 0.7 & 0.373 \\
\hline Gilaki & 135 & 29.6 & 1.5 & 0.000 & 81 & 17.6 & 0.9 & 0.618 & 40 & 9.0 & 1.3 & 0.147 \\
\hline Arab & 63 & 24.2 & 1.1 & 0.549 & 25 & 9.1 & 0.4 & 0.001 & 10 & 3.8 & 0.6 & 0.112 \\
\hline Turkman & 26 & 13.5 & 0.6 & 0.049 & 21 & 15.7 & 0.7 & 0.219 & 2 & 0.8 & 0.1 & 0.010 \\
\hline Other & 30 & 20.7 & 1.0 & 0.941 & 39 & 22.3 & 1.2 & 0.374 & 18 & 11.0 & 1.9 & 0.027 \\
\hline \multicolumn{13}{|l|}{ Employment status } \\
\hline Employee & 225 & 29.8 & 1.0 & - & 255 & 31.2 & 1.0 & 0.000 & 104 & 14.0 & 1.0 & - \\
\hline Labor & 84 & 25.8 & 0.5 & 0.008 & 57 & 13.7 & 0.2 & 0.000 & 22 & 8.2 & 0.2 & 0.000 \\
\hline Self-employed & 223 & 15.0 & 0.3 & 0.000 & 241 & 16.5 & 0.3 & 0.000 & 58 & 4.4 & 0.2 & 0.000 \\
\hline Student/soldier & 514 & 27.7 & 0.6 & 0.000 & 372 & 27.0 & 0.3 & 0.000 & 138 & 12.6 & 0.4 & 0.000 \\
\hline Homemaker & 1,025 & 21.9 & 0.7 & 0.001 & 751 & 11.1 & 0.4 & 0.000 & 244 & 3.2 & 0.4 & 0.000 \\
\hline Retired & 149 & 10.9 & 0.5 & 0.000 & 133 & 22.3 & 0.4 & 0.000 & 54 & 5.2 & 0.5 & 0.004 \\
\hline Unemployed & 142 & 19.4 & 0.6 & 0.001 & 109 & 15.0 & 0.4 & 0.000 & 46 & 6.8 & 0.5 & 0.001 \\
\hline
\end{tabular}




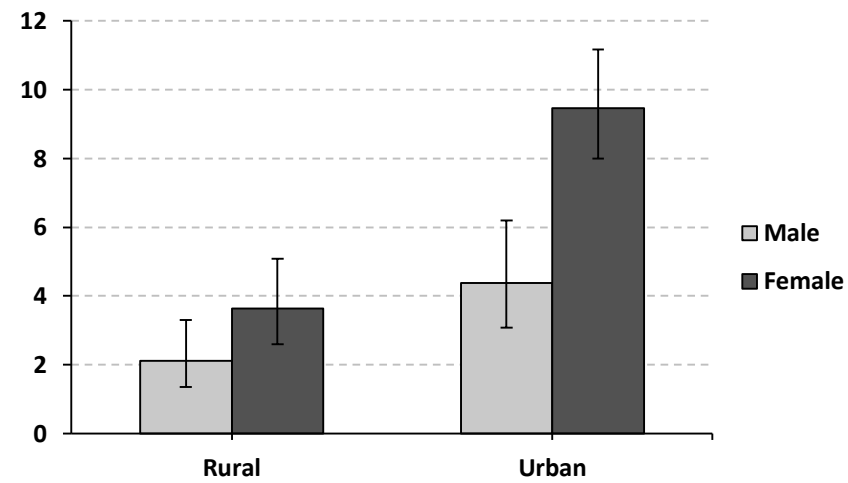

Figure 1. Percentage who brush twice or more a day and floss at least once a day over residential areas by gender.

a significant higher amount of this index compared to men especially for middle age groups. The same pattern was also seen for rural and urban people over age groups.

Among ethnicity categories, the best situation of $\mathrm{OH}$ was observed in Persians (6.4\%). Afterwards, Azaries, Lors, Kurds, Balouchs, Gilakis and Arabs take the next places respectively. The lowest prevalence belonged to Turkmens' people $(0.8 \%)$. Table 2 also compares the $\mathrm{OH}$ situation among different job categories. Employees whether governmental or nongovernmental had the highest degrees of $\mathrm{OH}$ (29.8\%), and the

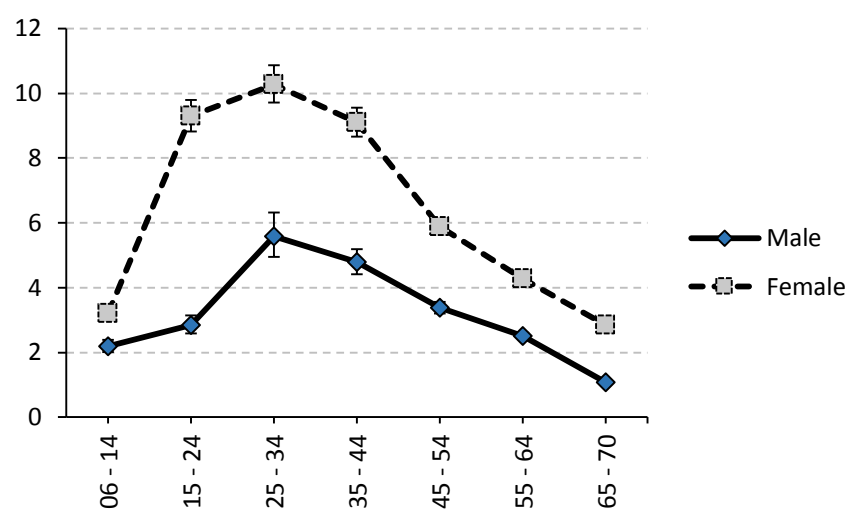

Figure 2. Percentage who brush twice or more a day and floss at least once a day over age groups by gender.

lowest was seen in retired persons (10.9\%).

Table 3 has been drawn to assess the impact of education and economic situation on $\mathrm{OH}$ by gender. All three relative frequencies of $\mathrm{OH}$ habits show upward trends by increasing the level of education $(P<0.001)$. Similar significant increment was observed in both crude and adjusted ORs over educational levels. Figure 3 illustrates the association between $\mathrm{OH}$ and level of education by gender. Values of percentages and relevant ORs also disclosed stronger impact of education on $\mathrm{OH}$ in females compared to men.

Table 3. Association between $\mathrm{OH}$ and two major SES factors; educational level and economic situation

\begin{tabular}{|c|c|c|c|c|c|c|c|c|c|c|c|c|}
\hline \multirow[b]{2}{*}{ Variable } & \multicolumn{4}{|c|}{ Brush $\geq$ twice/day } & \multicolumn{4}{|c|}{ Floss $\geq$ once/day } & \multicolumn{4}{|c|}{ Both habits/day } \\
\hline & $\%$ & $\begin{array}{c}\text { Crude } \\
\text { OR }^{\mathrm{a}}\end{array}$ & $\begin{array}{c}\text { Adjusted } \\
\text { OR }^{\mathrm{b}}\end{array}$ & $\begin{array}{l}P \text { for } \\
\text { Trend }\end{array}$ & $\%$ & $\begin{array}{c}\text { Crude } \\
\text { OR }^{\mathrm{a}}\end{array}$ & $\begin{array}{c}\text { Adjusted } \\
\text { OR }^{b}\end{array}$ & $\begin{array}{l}P \text { for } \\
\text { Trend }^{c}\end{array}$ & $\%$ & $\begin{array}{c}\text { Crude } \\
\text { OR }^{\mathrm{a}}\end{array}$ & $\begin{array}{c}\text { Adjusted } \\
\text { OR }^{b}\end{array}$ & $\begin{array}{l}P \text { for } \\
\text { Trend }\end{array}$ \\
\hline \multicolumn{13}{|l|}{ Males } \\
\hline Illiterate & 13.4 & 1.0 & 1.0 & 0.000 & 5.2 & 1.0 & 1.0 & 0.000 & 3.0 & 1.0 & 1.0 & 0.000 \\
\hline Primary school & 9.6 & 1.4 & 1.3 & & 6.8 & 1.5 & 1.4 & & 1.0 & 1.0 & 1.0 & \\
\hline Guidance school & 10.6 & $1.8^{*}$ & $1.7^{*}$ & & 10.2 & $2.5^{* *}$ & $2.3^{* *}$ & & 2.5 & 2.3 & 2.3 & \\
\hline Associate degree & 22.6 & $4.8^{* *}$ & $4.4^{* *}$ & & 24.9 & $8.1^{* *}$ & $7.1^{* *}$ & & 8.8 & $8.8^{* *}$ & $8.1^{* *}$ & \\
\hline Graduate & 20.3 & $4.5^{* *}$ & $4.1^{* *}$ & & 35.3 & $10.0^{* *}$ & $8.5^{* *}$ & & 9.7 & $11.2^{* *}$ & $10.2^{* *}$ & \\
\hline Post graduate & 26.1 & $5.1^{* *}$ & $4.6^{* *}$ & & 33.0 & $16.5^{* *}$ & $14.2^{* *}$ & & 10.0 & $15.2^{* *}$ & $13.6^{*}$ & \\
\hline \multicolumn{13}{|l|}{ Economic status } \\
\hline 1st quartile & 11.5 & 1.0 & 1.0 & 0.000 & 6.9 & 1.0 & 1.0 & 0.000 & 1.4 & 1.0 & 1.0 & 0.000 \\
\hline 2nd quartile & 12.0 & 1.0 & 0.9 & & 8.8 & 1.3 & 1.2 & & 2.1 & 1.3 & 1.2 & \\
\hline 4th quartile & 17.6 & $1.6^{*}$ & 1.4 & & 23.6 & $3.9^{* *}$ & $3.4^{* *}$ & & 7.1 & $4.9^{* *}$ & $4.0^{* *}$ & \\
\hline \multicolumn{13}{|l|}{ Females } \\
\hline \multicolumn{13}{|l|}{ Educational level } \\
\hline Illiterate & 16.6 & 1.0 & 1.0 & 0.000 & 7.2 & 1.0 & 1.0 & 0.000 & 2.9 & 1.0 & 1.0 & 0.000 \\
\hline Primary school & 22.2 & $1.6^{* *}$ & $1.5^{* *}$ & & 12.0 & $1.8^{* *}$ & $2.1^{* *}$ & & 3.4 & 1.3 & 1.5 & \\
\hline Guidance school & 27.9 & $2.3^{* *}$ & $2.2^{* *}$ & & 19.5 & $3.1^{* *}$ & $3.6^{* *}$ & & 6.9 & $3.1^{* *}$ & $3.4^{* *}$ & \\
\hline High school & 29.3 & $3.2^{* *}$ & $2.9^{* *}$ & & 26.8 & $5.7^{* *}$ & $6.1^{* *}$ & & 10.8 & $6.2^{* *}$ & $6.3^{* *}$ & \\
\hline Associate degree & 31.3 & $3.6^{* *}$ & $3.2^{* *}$ & & 35.1 & $8.0^{* *}$ & $8.5^{* *}$ & & 15.5 & $9.2^{* *}$ & $9.1^{* *}$ & \\
\hline Graduate & 37.1 & $4.2^{* *}$ & $3.7^{* *}$ & & 39.6 & $11.1^{* *}$ & $11.5^{* *}$ & & 20.2 & $11.6^{* *}$ & $11.2^{* *}$ & \\
\hline Post graduate & 47.6 & $7.1^{* *}$ & $6.4^{* *}$ & & 39.5 & $19.0^{* *}$ & $20.4^{* *}$ & & 20.0 & $19.0^{* *}$ & $19.2^{* *}$ & \\
\hline \multicolumn{13}{|l|}{ Economic status } \\
\hline 1st quartile & 23.3 & 1.0 & 1.0 & 0.000 & 10.5 & 1.0 & 1.0 & 0.000 & 3.3 & 1.0 & 1.0 & 0.000 \\
\hline 2nd quartile & 22.8 & 1.0 & 0.9 & & 16.6 & $1.7^{* *}$ & $1.5^{* *}$ & & 5.3 & $1.7^{*}$ & 1.5 & \\
\hline 3th quartile & 27.0 & 1.2 & 1.1 & & 20.5 & $2.2^{* *}$ & $1.8^{* *}$ & & 8.0 & $2.6^{* *}$ & $2.1^{*}$ & \\
\hline
\end{tabular}

$\mathrm{OH}=$ Oral Hygiene; SES= Socio-Economic Status; OR= Odds Ratio

adefined as OR's estimation without any adjustment' bdefined as OR's estimation by adjusting over gender, residential areas and age groups'; 'defined as $P$-value of Cochran-Armitage test for trend analysis.

${ }^{*} P<0.050 ;{ }^{* *} P<0.001$. 
After PCA, the first component (explaining $42 \%$ of the total variation) was utilized to categorize individuals into economic quartiles. As Figure 4 illustrates, for both genders, there is a significant increase in $\mathrm{OH}$ over economic quartiles $(P<0.001)$. Again a higher degree of association between economic status and $\mathrm{OH}$ was perceived in women relative to men.

In Table 4, we compared $\mathrm{OH}$ frequencies between individuals who are exposed to each common NCD risk factor and those who do not have the risk factor. As both values of crude and adjusted OR (I) illustrate, for people with unhealthy diet, physically inactive, current daily smokers, $\mathrm{OH}$ was significantly poorer than those who did not have these characteristics. The greatest difference in $\mathrm{OH}$ frequency was obtained between daily smokers and non-daily smokers $(\mathrm{OR}=3.3 ; P<0.001)$. Furthermore, by adjusting over education and economic status (adjusted II), only physical activity was found to be statistically correlated with $\mathrm{OH}(\mathrm{OR}=1.5 ; P<0.001)$. Figure 5 shows recommended daily $\mathrm{OH}$ frequencies over the number of risk factors people had. As depicted, by increasing the number of risk factors all three combinations of $\mathrm{OH}$ habits gently decrease $(\mathrm{OR}=0.7 ; P<0.001)$.

\section{Discussion}

In this paper, we made an attempt to investigate dental selfcare practices among Iranian population aged 6-70 years. To our knowledge, this was the first effort to estimate $\mathrm{OH}$ status in a general population with a national scale in the country. Overall, our results revealed a very low prevalence of people with recommended $\mathrm{OH}$ practices in Iran. We also found that Iranian men have much less attention to their $\mathrm{OH}$ compared to women. In addition, rural inhabitants are much more than urban citizens at risk for dental caries due to their lower degrees of $\mathrm{OH}$. Maximum tendency to $\mathrm{OH}$ practices was also perceived by adults in age group 25-34. Persians and Turkmens among ethnic groups and employees and retirees among job categories respectively had the best and worst circumstances. We also identified socio-economic determinants (including educational level and assets) as one of the most influential factors on people's dental care habits.
There were a significant interrelation between $\mathrm{OH}$ and fruit/ vegetable consumption, physical activity and smoking as well.

\section{Oral Hygiene $(\mathrm{OH})$ status in Iran}

To our surprise, current data show that although there was a remarkable decrease in dental caries from DMFT of 4 to 1.5 in 12 -year-old children (40-44), oral self-care status is not still

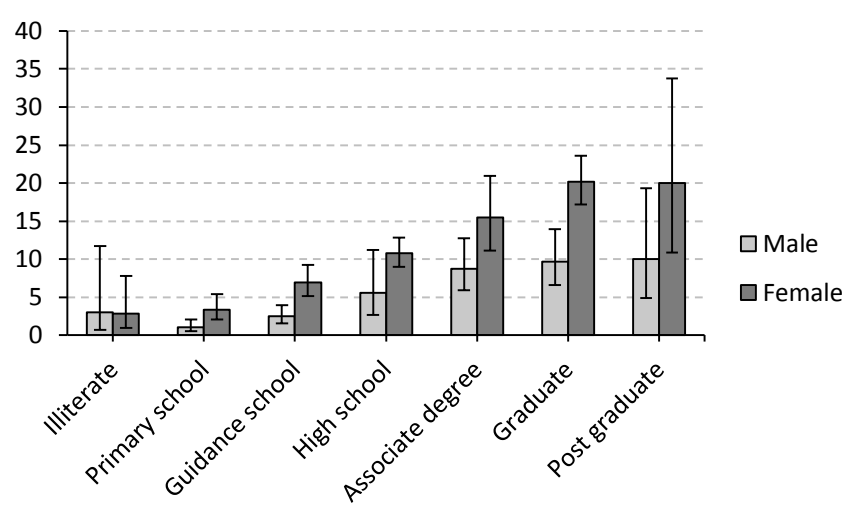

Figure 3. Percentage who brush twice or more a day and floss at least once a day over educational level by gender

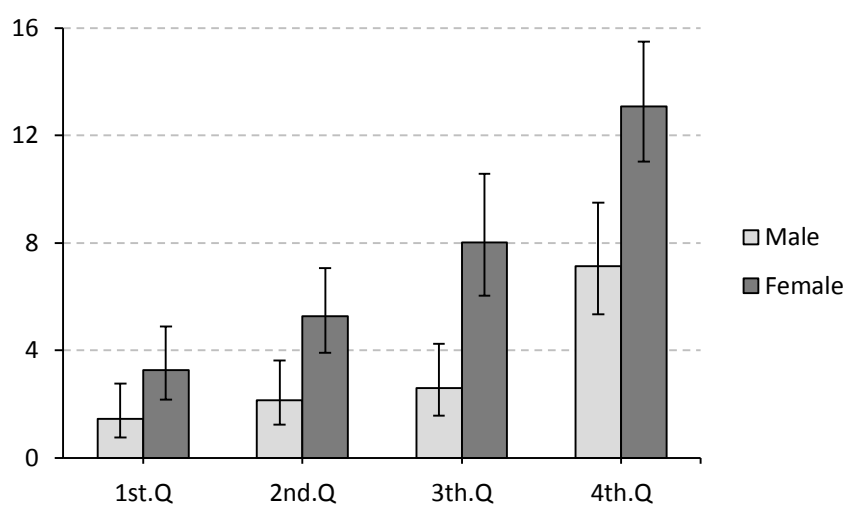

Figure 4. Percentage who brush twice or more a day and floss at least once a day over economic quartiles by gender

Table 4. Association between $\mathrm{OH}$ status and common risk factors of NCDs

\begin{tabular}{|c|c|c|c|c|c|c|c|}
\hline \multirow{2}{*}{ Risk Factor } & \multirow{2}{*}{$\%$} & \multicolumn{2}{|c|}{ Crude $^{a}$} & \multicolumn{2}{|c|}{ Adjusted I } & \multicolumn{2}{|c|}{ Adjusted II } \\
\hline & & OR & $P$ & OR & $P$ & OR & $P$ \\
\hline \multicolumn{8}{|l|}{ Diet } \\
\hline Poor $^{d}$ & 5.0 & 1.0 & - & 1.0 & - & 1.0 & - \\
\hline Healthy & 9.5 & 1.8 & 0.000 & 1.6 & 0.000 & 1.3 & 0.065 \\
\hline \multicolumn{8}{|l|}{ Physical activity } \\
\hline Low $^{e}$ & 4.5 & 1.0 & - & 1.0 & - & 1.0 & - \\
\hline Moderate/Vigorous & 7.0 & 1.2 & 0.006 & 1.4 & 0.001 & 1.5 & 0.001 \\
\hline \multicolumn{8}{|l|}{ Tobacco use } \\
\hline Daily smoker & 1.6 & 1.0 & - & 1.0 & - & 1.0 & - \\
\hline Non-daily smoker & 7.5 & 3.3 & 0.000 & 1.9 & 0.045 & 1.5 & 0.198 \\
\hline \multicolumn{8}{|l|}{ Obesity } \\
\hline Obese $^{f}$ & 4.1 & 1.0 & - & 1.0 & - & 1.0 & - \\
\hline Normal & 6.3 & 1.1 & 0.263 & 1.3 & 0.052 & 1.1 & 0.336 \\
\hline \multicolumn{8}{|l|}{ Hypertension } \\
\hline Normal & 5.7 & 1.2 & 0.074 & 1.2 & 0.079 & 1.0 & 0.959 \\
\hline
\end{tabular}

$\mathrm{OH}=$ Oral Hygiene; NCDs= Non-Communicable Diseases; $P=P$-value for comparison test of proportions

${ }^{a}$ No adjustment was made; badjusted by gender, residential area and age group; 'adjusted by gender, residential area, age group, educational level and;

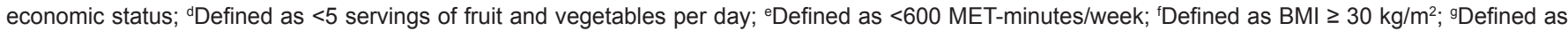
systolic blood pressure $\geq 140 \mathrm{mmHg}$ and/or diastolic blood pressure $\geq 90 \mathrm{mmHg}$. 


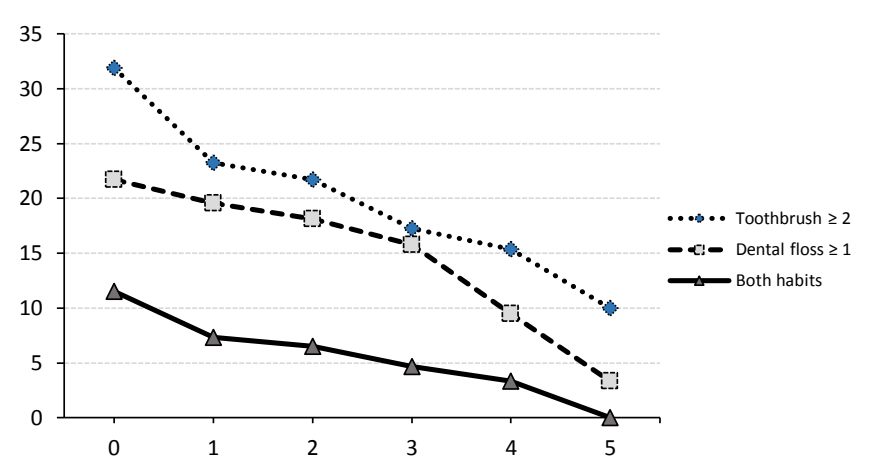

Figure 5. Relative frequencies of daily oral hygiene behaviors over the number of risk factors people were exposed

satisfactory In Iran. Kasmaei et al. have already expressed their concerns about dental health condition in Iran. They urged quick action for $\mathrm{OH}$ education in our community (45). Only $5.7 \%$ of total population met the minimum recommendations for daily tooth brushing and flossing. About 32.5\% did not brush their teeth even once per day, and only $20.1 \%$ brush at least twice a day. Moreover, $83.2 \%$ of the population did not use dental floss on a daily basis. In the other side $3.4 \%$ stated that they floss at least once a day. In a study in Denmark 68\% of dentate populations reported tooth brushing at least twicedaily and $11 \%$ dental flossing (46).

Women were more than twice likely to have their teeth cleaned $(\mathrm{OR}=2.3)$. This superiority was maintained in any age group, residential district, level of education and economic status. Similar results have been reported in previous studies (4749). It can be inferred that this difference originate from the higher attention to appearance by women. Besides, there was seen a neat discrepancy regarding dental self-care practices between urban citizens compared to the villagers $(\mathrm{OR}=2.7)$, this finding is in compliance with another studies $(47,50,51)$. We believe that this condition may be due to the lack of adequate knowledge on general health and less attention to appearance in rural areas.

Among school age children (6-14 years old) $14.3 \%$ brush their teeth twice a day, 9.4\% use floss daily and only $2.7 \%$ meet both criteria. In a recent study in Tanzania, Mashoto et al. reported that $21.9 \%$ of their study population which were schoolchildren never brushed their teeth and only 32.9\% met the standard criteria for tooth brushing (52). In their latest resolution, WHO urged all communities to develop and implement oral health promotion programs in school children as part of activities in health-promoting schools (53). Assuming schoolchildren as referent, higher frequencies of tooth brushing and flossing was seen amongst 25-34-yearold persons between $(\mathrm{OR}=3.3)$ for both genders. In general, people aged 24-34 more than twice the first age group brush at least twice a day/floss daily $(\mathrm{OR} \geq 2.4)$. Age distribution of dental self-care behaviors sheds light on a precious point which should be considered in the future via health policy-makers. Since the worst condition belongs to the youngest group and fortunately there is the possibility of health education to these groups through schools we will need to design and perform appropriate interventions for them.

Although we do not have any data about the proportion of denture user adults in our sample, considering the fact that the worst oral health condition belongs to elderly people, Lack of health knowledge, traditions and cultural unhealthy beliefs might affect dental self-care practices in these populations. With regard to the elderly's special needs for treatment, policy-makers should prepare facilities to better treat this age group. Hence, further studies in this area seem to be necessary (54-56). Also poor $\mathrm{OH}$ in younger participants brings up the need for implementation of preventive policies for this group. Considering the findings from other studies increasing oral health literacy through school and family education together may result in successful achievements (57-59).

In Iran as a country with diverse ethnic groups, there was an ethnic disparity in dental self-care habits as well. Considering Persians as baseline, we saw that except for Gilakis who had better condition in taking both tooth brushing and flossing recommendations $(\mathrm{OR}=1.3)$, unhealthy behaviors among other subpopulations were more common than Persians $(\mathrm{OR}<1)$. The worst situation belonged to Turkmens $(\mathrm{OR}=0.1)$; only $0.8 \%$ of them were used to respect the recommendations for daily $\mathrm{OH}$. This calls for not only further studies to explore the reasons behind this negligence, but provision of appropriate interventions as well. Higher incidence of upper gastrointestinal cancers especially esophageal cancer among Turkmen populations might also have roots in their poor $\mathrm{OH}$. There are at least two evidences which reported the significant correlation between dental self-care behaviors including tooth brushing and esophageal cancer in Turkmens of Iran $(1,460)$. Also in another study Nasrollahzadeh et al. demonstrated a possible interaction between gastric atrophy and poor $\mathrm{OH}$ in developing esophageal squamous cell carcinoma in an Iranian population (12).

\section{Oral Hygiene $(\mathrm{OH})$ and socio-economic factors}

Current results revealed that after adjustment by gender, age and residential area there was obvious educational gradient with respect to unhealthy dental practices; in a way that illiterates and less educated people had more detrimental habits. The chance of having healthy dental practice among university graduates was beyond nine times more than those with lowest degree. Additionally, this impact was more obvious in females than males. This finding was alike with previous studies as well, for example in one of them researchers reported that the odds of having dental self-care habits amongst university graduates were more than six times those without graduate degrees $(49,61)$.

Dental self-care behaviors were less common among people with poorer economic status. After adjusting for gender, age and residential area there seem an ascending trend between health-related behaviors and economic status. Likewise, in Tanzania, utilizing tooth brush was less common among adolescents from lower economic status (52). Also in a Korean study there was significant correlation between regular tooth brushing habits and individual's income (48). However, it appears that the impact of education on $\mathrm{OH}$ is much stronger than financial capability.

Oral Hygiene (OH) and Non-Communicable Disease (NCD) risk factors

Another important finding we observed in this study is the interrelation between NCD risk factors and unhealthy personal practices of dental health. The clustering among 
these factors underlines the common risk factors approach in Iranian population (62). As we brought in Table 4, values of both crude and adjusted (I) OR reflect a significant positive correlation between oral health compromising practices and behavioral risk factors: physical inactivity, smoking and unhealthy diet. In this part, obesity and hypertension were not significantly correlated with $\mathrm{OH}$, though there are some evidences which relate $\mathrm{OH}$ to obesity and hypertension $(63,64)$. Moreover, those people who had more risk factors were more likely to neglect their $\mathrm{OH}$, according to Figure 5. In a British study, researchers found same correlations between similar variables (high sugar consumption, smoking) (61). In Korea, a larger proportion of people who had reasonable physical activity had regular tooth brushing habit as well (48). There are studies that already illustrated the link between health related behaviors like smoking, frequency of dental visits, frequency of eating fresh fruits and vegetables to oral health (65-67).

While we eliminated the effect of SES by including education and economic status in the model, only physical activity remained significant. This clearly demonstrates that SES plays a confounding role in the association between $\mathrm{OH}$ and behavioral risk factors except for physical inactivity. For instance, lack of education causes both poor $\mathrm{OH}$ and poor dietary habits. About physical activity, it can be inferred that people with sedentary lifestyle pay less attention to their basic health aside from their educational or economic levels.

Various studies have demonstrated the effectiveness of application of social and behavioral models in NCD prevention and control $(68,69)$. Likewise, Dorri and colleagues' behavioral model showed that dental self-care behaviors and general hygiene behaviors are strongly correlated to each other (70). In this regard, it seems that to obtain successful community-wide health education promotion programs involving $\mathrm{OH}$ we should not neglect behavioral theories upon designing strategic national programs.

\section{Strengths}

This survey was carried out in a national scale and on a general population, so the results are representative of the whole country. Another eminent advantage of this study was the use of the standard questions of WHO STEPS project which is regularly being performed by a significant number of countries around the world. So it enables us to compare our results with findings of other countries and evaluate ourselves in an international level.

The second strength of this study is that even though previous studies have already confirmed existence of a positive association between poor $\mathrm{OH}$ and lifestyle risk factors they did not considered the probable confounding variables. We showed that the association between $\mathrm{OH}$ and those risk factors were through confounding effect of SES except for physical activity.

\section{Limitations}

One limitation of this study was due to sampling design. Since the sample was not stratified by provinces, we could not estimate and compare $\mathrm{OH}$ condition among provinces. Locating hotspots and prioritizing the regions with poorer situations for effective interventions could be an advantage of using stratification technique in sampling scheme. Although the current study has been the sixth round of the national NCD risk factors surveys in Iran, it was the first time that $\mathrm{OH}$ habits were measured. As a result, considering the trends on $\mathrm{OH}$ conditions over time was impossible.

The other shortcoming to our work is that the frequency of being visited by dentist, as important aspect of $\mathrm{OH}$, was neglected in the questionnaire. Furthermore, lack of information on individuals' denture state made us unable to exclude denture users for subsequent analyses; it casts doubt on the estimates particularly in older age groups. Additional information such as fluoride intake, utilizing toothpick or mouthwash, consumption of sugar and chewing gum, age at first use toothbrush could also capture other dimensions of $\mathrm{OH}$. Besides, through some simple self-reported questions, we were also able to assess individuals' oral health by computing basic indices (DMFT, DMFS and deft) for dental caries. Nevertheless, $\mathrm{OH}$ was only a small part of a long questionnaire of NCD risk factors survey, and including extra questions might cause response bias and weaken the validity of our instrument.

\section{Conclusion}

Our findings generally emphasize on the need for improving oral health facilities among rural people. It also underlines the need to enhance oral self-care maintenance behaviors specifically in the youngest age group 6-14 years old in both rural and urban regions and calls for early preventive strategies and instructive programs. Moreover, SES, especially education, was determined as a very important determinant for $\mathrm{OH}$. Therefore, the pivotal role of education and equity should be taken into consideration when we are going to design and implement new interventions. However, due to limited resources, it would not be logical to apply these programs at a national level; considering the subgroups at higher risk, it seems that designing educative strategies for the most high risk subgroups who can benefit the most is appropriate $(49,71)$.

The strong association between $\mathrm{OH}$ and behavioral risk factors introduces $\mathrm{OH}$ as a good representative for other lifestyle components, i.e. we can make a relatively fair judgment about people's other risky behaviors only by knowing about their $\mathrm{OH}$. However, for diet and smoking, this interrelation seems to be indirect through socio-economic factors. Thus, by planning intervention programs based on raising literacy and equity within the community, we expect not only would decrease oral problems, but also burden of other NCDs.

In spite of ongoing health programs, Oral health situation in Iran requires urgent strategic programs. Hopefully better conditions can be achieved through promoting the community's educational level and establishment of social justice.

\section{Clinical relevance \\ Scientific rationale for study}

There is not adequate evidence about the $\mathrm{OH}$ status in the general population of Iran. Socio-economic determinants seem to have a remarkable contribution to $\mathrm{OH}$ behaviors and 
make them relevant to other lifestyle factors.

\section{Acknowledgments}

The current study was a part of the National NCD Risk Factors Surveillance Program, 2011, which was supported and funded by Iran's Ministry of Health and Medical Education (MoHME). Our special gratitude goes to the senior experts and staff in diseases control and prevention departments of Deputy for Health located in all 51 Medical Universities across the country, interviewers and researchers of the STEPS team who conducted the entire processes of the survey. We also would like to thank all the participants in this study who gave us their invaluable time and information.

\section{Ethical issues}

All the ethical considerations of the study have been approved by the board of Center for NCD Control and Prevention. Moreover, the entire samples received and approved an informed consent before entering the study.

\section{Competing interests}

The authors declare that they have no competing interests.

\section{Authors' contributions}

AR: contribution to study implementation and data gathering, data analysis and providing the manuscript; FA: contribution to study implementation, data gathering and providing the manuscript; $\mathrm{AM}$ : contribution to data analysis and providing manuscript; JK: contribution to study implementation, data gathering and providing manuscript; KE: contribution to study implementation and data gathering

\section{Authors' affiliations}

${ }^{1}$ Center for Disease Control and Prevention, Deputy for Health, Ministry of Health and Medical Education, Tehran, Iran. ${ }^{2}$ Cancer Research Center, Cancer Institute of Iran, Tehran University of Medical Sciences, Tehran, Iran. ${ }^{3}$ Department of Community Medicine, Iran University of Medical Sciences, Tehran, Iran. ${ }^{4}$ Department of Epidemiology, School of Public Health, ShahidBeheshti University of Medical Sciences, Tehran, Iran. ${ }^{5}$ National Program for Disease Registries and Health Outcomes, Deputy for Research, Ministry of Health and Medical Education, Tehran, Iran.

\section{References}

1. Lim SS, Vos T, Flaxman AD, Danaei G, Shibuya K, Adair-Rohani $\mathrm{H}$, et al. A comparative risk assessment of burden of disease and injury attributable to 67 risk factors and risk factor clusters in 21 regions, 1990-2010: a systematic analysis for the Global Burden of Disease Study 2010. Lancet 2013; 380: 2224-60. doi: 10.1016/S0140-6736(12)61766-8

2. World Health Organization (WHO). Global health risks: mortality and burden of disease attributable to selected major risks. Geneva: WHO; 2009.

3. Mathers C, Fat DM, Boerma J. The global burden of disease: 2004 update. Geneva: WHO; 2008.

4. Allender S, Lacey B, Webster P, Rayner M, Deepa M, Scarborough $\mathrm{P}$, et al. Level of urbanization and noncommunicable disease risk factors in Tamil Nadu, India. Bull World Health Organ 2010; 88: 297-304. doi: 10.2471/blt.09.065847

5. Hosseinpoor AR, Bergen N, Kunst A, Harper S, Guthold R, Rekve D, et al. Socioeconomic inequalities in risk factors for non communicable diseases in low-income and middle-income countries: results from the World Health Survey. BMC Public Health 2012; 12: 912. doi: 10.1186/1471-2458-12-912

6. Hessari H, Vehkalahti MM, Eghbal MJ, Murtomaa HT. Oral health among 35-to 44-year-old Iranians. Med Princ Pract 2007;16: 280-5. doi: 10.1159/000102150

7. Bloom DE, Shannon S. The Demography of Aging. Molecular
Aspects of Aging: Understanding Lung Aging. John Wiley \& Sons; 2014. p. 1-12.

8. Mbawalla HS, Masalu JR, Åstrøm AN. Socio-demographic and behavioural correlates of oral hygiene status and oral health related quality of life, the Limpopo-Arusha school health project (LASH): A cross-sectional study. BMC Pediatr 2010; 10: 87. doi: 10.1186/1471-2431-10-87

9. Sheiham A. Oral health, general health and quality of life. Bull World Health Organ 2005; 83: 644.

10. Locker D, Quiñonez C. To what extent do oral disorders compromise the quality of life? Community Dent Oral Epidemiol 2011; 39: 3-11. doi: 10.1111/j.1600-0528.2010.00597.x

11. Tezal M, Scannapieco FA, Wactawski-Wende J, Meurman JH, Marshall JR, Rojas IG, et al. Dental Caries and Head and Neck Cancers. JAMA Otolaryngol Head Neck Surg 2013; 139: 105460. doi: 10.1001/jamaoto.2013.4569

12. Nasrollahzadeh D, Malekzadeh R, Aghcheli K, Sotoudeh M, Merat S, Islami F, et al. Gastric atrophy and oesophageal squamous cell carcinoma: possible interaction with dental health and oral hygiene habit. Br J Cancer 2012; 107: 888-94.

13. Dar N, Islami F, Bhat G, Shah I, Makhdoomi M, Iqbal B, et al. Poor oral hygiene and risk of esophageal squamous cell carcinoma in Kashmir. Br J Cancer 2013; 109: 1367-72. doi: $10.1111 /$ cas. 12210

14. Abnet CC, Kamangar F, Islami F, Nasrollahzadeh D, Brennan $\mathrm{P}$, Aghcheli $\mathrm{K}$, et al. Tooth loss and lack of regular oral hygiene are associated with higher risk of esophageal squamous cell carcinoma. Cancer Epidemiol Biomarkers Prev 2008; 17: 30628. doi: 10.1158/1055-9965.epi-08-0558

15. American Dental Association (ADA). Statement on Regular Brushing and Flossing to Help Prevent Oral Infections. American Dental Association; 2013.

16. Lapin B, Smith AJ. Dental Care: The Often Neglected Part of Health Care. New Haven, CT: Yale University; 2008.

17. Glick M, Monteiro da Silva O, Seeberger GK, Xu T, Pucca G, Williams DM, et al. FDI Vision 2020: shaping the future of oral health. Int Dent J 2012; 62: 278-91. doi: 10.1111/idj.12009

18. Marcenes W, Kassebaum N, Bernabé E, Flaxman A, Naghavi M, Lopez A, et al. Global Burden of Oral Conditions in 19902010 A Systematic Analysis. J Dent Res 2013; 92: 592-7. doi: 10.1177/0022034513490168

19. Petersen PE, Ogawa $\mathrm{H}$. The global burden of periodontal disease: towards integration with chronic disease prevention and control. Periodontology 2000 2012; 60: 15-39. doi: 10.1111/j.1600-0757.2011.00425.x

20. Petersen PE. The World Oral Health Report 2003: continuous improvement of oral health in the 21st century-the approach of the WHO Global Oral Health Programme. Community Dent Oral Epidemiol 2003; 31: 3-24. doi: 10.1046/j..2003.com122.x

21. Petersen PE, Baehni PC. Periodontal health and global public health. Periodontology 2000 2012; 60: 7-14. doi: 10.1111/j.16000757.2012.00452.x

22. Petersen PE, Bourgeois D, Ogawa H, Estupinan-Day S, Ndiaye C. The global burden of oral diseases and risks to oral health. Bull World Health Organ 2005; 83: 661-9.

23. Petersen PE, Hoerup N, Poomviset N, Prommajan J, Watanapa A. Oral health status and oral health behaviour of urban and rural schoolchildren in Southern Thailand. Int Dent J 2001; 51: 95102. doi: 10.1002/j.1875-595x.2001.tb00829.x

24. Ismail Al, Sohn W. The impact of universal access to dental care on disparities in caries experience in children. J Am Dent Assoc 2001; 132: 295-303. doi: 10.14219/jada.archive.2001.0172

25. Paulander J, Axelsson P, Lindhe J. Association between level of education and oral health status in 35, 50,65and 75yearolds. J Clin Periodontol 2003; 30: 697-704. doi: 10.1034/j.1600- 
051x.2003.00357.x

26. Manski RJ, Magder LS. Demographic and socioeconomic predictors of dental care utilization. J Am Dent Assoc 1998; 129: 195-200. doi: 10.14219/jada.archive.1998.0177

27. Sabbah W, Tsakos G, Sheiham A, Watt RG. The role of health-related behaviors in the socioeconomic disparities in oral health. Soc Sci Med 2009; 68: 298-303. doi: 10.1016/j. socscimed.2008.10.030

28. Polk DE, Weyant RJ, Manz MC. Socioeconomic factors in adolescents' oral health: are they mediated by oral hygiene behaviors or preventive interventions? Community Dent Oral Epidemiol 2010; 38: 1-9. doi: 10.1111/j.1600-0528.2009.00499.x

29. Petersen PE. Sociobehavioural risk factors in dental cariesinternational perspectives. Community Dent Oral Epidemiol 2005; 33: 274-9. doi: 10.1111/j.1600-0528.2005.00235.x

30. Rao VK, Balan A. The influence of socio economic status on dental caries in Indian children. Int J Adv Life Sci 2013; 6: 52731.

31. Johnson NW, Warnakulasuriya S, Gupta P, Dimba E, Chindia $\mathrm{M}$, Otoh $\mathrm{E}$, et al. Global oral health inequalities in incidence and outcomes for oral cancer causes and solutions. Adv Dent Res 2011; 23: 237-46. doi: 10.1177/0022034511402082

32. Watt R, Sheiham A. Health policy: Inequalities in oral health: a review of the evidence and recommendations for action. $\mathrm{Br}$ Dent J 1999; 187: 6-12. doi: 10.1038/sj.bdj.4800191

33. Brennan D, Spencer A. Childhood Oral Health and SES Predictors of Caries in 30-Year-Olds. Caries Res 2014; 48: 23743. doi: 10.1159/000354044

34. Petersen PE. Global policy for improvement of oral health in the 21st century-implications to oral health research of World Health Assembly 2007, World Health Organization. Community Dent Oral Epidemiol 2009; 37: 1-8. doi: 10.1111/j.16000528.2008.00448.x

35. Faulks D, Freedman L, Thompson S, Sagheri D, Dougall A. The value of education in special care dentistry as a means of reducing inequalities in oral health. Eur J Dent Educ 2012; 16: 195-201. doi: 10.1111/j.1600-0579.2012.00736.x

36. Kowash M, Pinfield A, Smith J, Curzon M. Dental health education: effectiveness on oral health of a long-term health education programme for mothers with young children. $\mathrm{Br}$ Dent $J$ 2000; 188: 201-5. doi: 10.1038/sj.bdj.4800431a

37. Petersen PE, Peng B, Tai B, Bian Z, Fan M. Effect of a schoolbased oral health education programme in Wuhan City, Peoples Republic of China. Int Dent J 2004; 54: 33-41. doi: 10.1111/j.1875595x.2004.tb00250.x

38. Wierzbicka M, Petersen PE, Szatko F, Dybizbanska E, Kalo I. Changing oral health status and oral health behaviour of schoolchildren in Poland. Community Dent Health 2002; 19: 243-50.

39. Rong WS, Bian JY, Wang WJ, De Wang J. Effectiveness of an oral health education and caries prevention program in kindergartens in China. Community Dent Oral Epidemiol 2003; 31: 412-6.

40. Pakshir HR. Oral health in Iran. Int Dent $J$ 2004; 54: 367-72.

41. Pakpour A, Hidarnia A, Hajizadeh E, Kumar S, Fridlund B. Why Iranian adolescents do not brush their teeth: a qualitative study. Int J Dent Hyg 2012; 10: 86-90. doi: 10.1111/j.16015037.2011.00513.x

42. Sanei AS, Nikbakht-Nasrabadi A. Periodontal health status and treatment needs in Iranian adolescent population. Arch Iran Med 2005; 8: 290-4.

43. Yazdani R, Vehkalahti M, Nouri M, Murtomaa H. Oral health and treatment needs among 15-year-olds in Tehran, Iran. Community Dent Health 2008; 25: 221-5.

44. Pakpour AH, Hidarnia A, Hajizadeh E, Kumar S, Harrison AP.
The status of dental caries and related factors in a sample of Iranian adolescents. Med Oral Patol Oral Cir Bucal 2011; 16: e822-7. doi: 10.4317/medoral.17074

45. Kasmaei P, Shokravi FA, Hidarnia A, Hajizadeh E, AtrkarRoushan Z, Shirazi KK, et al. Brushing behavior among young adolescents: does perceived severity matter. BMC Public Health 2014; 14: 8. doi: 10.1186/1471-2458-14-8

46. Christensen LB, Petersen PE, Krustrup U, Kjøller M. Selfreported oral hygiene practices among adults in Denmark. Community Dent Health 2003; 20: 229-35.

47. Harada S, Akhter R, Kurita K, Mori M, Hoshikoshi M, Tamashiro H, et al. Relationships between lifestyle and dental health behaviors in a rural population in Japan. Community Dent Oral Epidemiol 2005; 33: 17-24. doi: 10.1111/j.1600-0528.2004.00189.x

48. Kim CS, Han SY, Kim CW. The relationship between regional socioeconomic position and oral health behavior: A multilevel approach analysis. J Korean Acad Oral Health 2013; 37: 20815. doi: 10.11149/jkaoh.2013.37.4.208

49. Ronis DL, Lang WP, Farghaly MM, Passow E. Tooth Brushing, Flossing, and Preventive Dental Visits by Detroitarea Residents in Relation to Demographic and Socioeconomic Factors. J Public Health Dent 1993; 53: 138-45. doi: 10.1111/j.1752-7325.1993. tb02692.x

50. Demirer S, Gursoy U, Ozdemir H, Erdemir E, Uitto V. Periodontal health knowledge and smoking are associated with periodontal treatment need according to tooth brushing levels. West Indian Med J 2012; 61: 191-7.

51. Varenne B, Petersen PE, Ouattara S. Oral health behaviour of children and adults in urban and rural areas of Burkina Faso, Africa. Int Dent J 2006; 56: 61-70. doi: 10.1111/j.1875-595x.2004. tb00260.x

52. Mashoto KO, Astrom AN, Skeie MS, Masalu JR. Sociodemographic disparity in oral health among the poor: a cross sectional study of early adolescents in Kilwa district, Tanzania. BMC Oral Health 2010; 10: 7. doi: 10.1186/1472-6831-10-7

53. Petersen PE. Improvement of global oral health-the leadership role of the World Health Organization. Community Dent Health 2010; 27: 194-8.

54. Dickinson C, Beatty C, Marshall D. A pilot study: are dental hygienists in Texas ready for the elderly population explosion? Int J Dent Hyg 2012; 10: 128-37. doi: 10.1111/j.16015037.2011.00526.x

55. Rabiei M, Kasemnezhad E, Shakiba M, Pourkay H. Prevalence of oral and dental disorders in institutionalised elderly people in Rasht, Iran. Gerodontology 2010; 27: 174-7. doi: 10.1111/j.17412358.2009.00313.x

56. Marchini L, Vieira P, Bossan T, Montenegro F, Cunha V. Selfreported oral hygiene habits among institutionalised elderly and their relationship to the condition of oral tissues in Taubaté, Brazil. Gerodontology 2006; 23: 33-7. doi: 10.1111/j.17412358.2006.00092.x

57. Yekaninejad MS, Eshraghian MR, Nourijelyani K, Mohammad $\mathrm{K}$, Foroushani AR, Zayeri F, et al. Effect of a school-based oral healtheducation program on Iranian children: results from a group randomized trial. Eur J Oral Sci 2012; 120: 429-37. doi: 10.1111/j.1600-0722.2012.00993.x

58. Dawani N, Qureshi A, Syed S. Integrated School-Based Child Oral Health Education. J Dow Univ Health Sci 2012; 6: 110-4.

59. Bhardwaj VK, Sharma KR, Luthra RP, Jhingta P, Sharma D, Justa A. Impact of school-based oral health education program on oral health of 12 and 15 years old school children. $J$ Educ Health Promot 2013; 2: 33. doi: 10.4103/2277-9531.115820

60. Sepehr A, Kamangar F, Fahimi S, Saidi F, Abnet CC, Dawsey SM. Poor oral health as a risk factor for esophageal squamous dysplasia in northeastern Iran. Anticancer Res 2005; 25: 543-6. 
61. Singh A, Rouxel P, Watt R, Tsakos G. Social inequalities in clustering of oral health related behaviors in a national sample of British adults. Prev Med 2013; 57: 102-6. doi: 10.1016/j. ypmed.2013.04.018

62. Sheiham A, Watt RG. The common risk factor approach: a rational basis for promoting oral health. Community Dent Oral Epidemiol 2000; 28: 399-406. doi: 10.1034/j.1600-0528.2000.028006399.x

63. Franchini R, Petri A, Migliario M, Rimondini L. Poor oral hygiene and gingivitis are associated with obesity and overweight status in paediatric subjects. J Clin Periodontol 2011; 38: 1021-8. doi: 10.1111/j.1600-051x.2011.01770.x

64. Alves LS, Susin C, Damé-Teixeira N, Maltz M. Overweight and obesity are not associated with dental caries among 12-year-old South Brazilian schoolchildren. Community Dent Oral Epidemiol 2013; 41: 224-31. doi: 10.1111/cdoe.12010

65. Ojima M, Hanioka T, Tanaka K, Aoyama H. Cigarette smoking and tooth loss experience among young adults: a national record linkage study. BMC Public Health 2007; 7: 313. doi: 10.1186/1471-2458-7-313
66. Moynihan P. The Role of Diet in the Prevention of Dental Diseases. In: Limeback $\mathrm{H}$, editor. Comprehensive Preventive Dentistry. John Wiley \& Sons; 2012. p. 99.

67. Haber J, Wattles J, Crowley M, Mandell R, Joshipura K, Kent $\mathrm{RL}$. Evidence for cigarette smoking as a major risk factor for periodontitis. J Periodontol 1993; 64: 16-23. doi: 10.1902/ jop.1993.64.1.16

68. Ding D, Zhong X, Lau JT, Oldenburg B. Behavioral medicine and prevention of non-communicable diseases in China: current challenges and future directions. Int J Behav Med 2014; 21: 5849. doi: 10.1007/s12529-014-9393-7

69. Glanz K, Bishop DB. The role of behavioral science theory in development and implementation of public health interventions. Annu Rev Public Health 2010; 31: 399-418.

70. Dorri M, Sheiham A, Watt RG. Modelling the factors influencing general and oral hygiene behaviours in adolescents. Int J Paediatr Dent 2010; 20: 261-9. doi: 10.1111/j.1365-263x.2010.01048.x

71. Rose G. Sick individuals and sick populations. Int J Epidemiol 2001; 30: 427-32. doi: 10.1093/ije/30.3.427 